\title{
Fixed Points on C-distance in Ordered Cone Metric Spaces
}

\author{
K. Prudhvi \\ Department of Mathematics, University College of Science, Osmania University, India
}

Copyright $(2017$ by authors, all rights reserved. Authors agree that this article remains permanently open access under the terms of the Creative Commons Attribution License 4.0 International License

\begin{abstract}
In this paper, we prove fixed point theorems on c-distance in ordered cone metric spaces. Our results generalize, extend and improve the recent results existing in the literature.
\end{abstract}

Keywords Cone Metric Space, Fixed Point, C-distance, Contractive Mapping

\section{Introduction and Preliminaries}

In 2007, Huang and Zhang [9] introduced the concept of a cone metric space, they replaced set of real numbers by an ordered Banach space and proved some fixed point theorems for contractive type conditions in cone metric spaces. Later on many authors have (for e.g., [1, 2, 3, 5, 6, 8, 12]) proved common fixed point theorems for different contractive type conditions in cone metric spaces. Some of the authors have studied fixed point theorems on partially ordered cone metric spaces (see, e.g., [3, 4, 11, 13]). In 2011, Y. J. Cho, et al. [7] introduced a concept of the c-distance in a cone metric spaces and proved some fixed point theorems in ordered cone metric spaces. In this paper, we obtained some fixed point theorems on c-distance in ordered cone metric spaces. Our results generalize, extend and improved the results of $Y$. J. Cho, et. al.[7].

The following definitions are due to [9].

Definition 1.1[9] Let $E$ be a real Banach space and $\theta$ denotes the zero element in $\mathrm{E}$. $\mathrm{P}$ be a subset of $\mathrm{E}$. The set $\mathrm{P}$ is called a cone if and only if:

(a). $\mathrm{P}$ is closed, non-empty and $\mathrm{P} \neq\{\theta\}$;

(b). $a, b \in \mathbb{R}, a, b \geq 0, x, y \in P$ implies $a x+b y \in P$;

(c). $P \cap(-P)=\{\theta\}$.

Definition 1.2[9] Let $P$ be a cone in a Banach space E, define partial ordering ' $\preccurlyeq$ ' with respect to $\mathrm{P}$ by $\mathrm{x} \preccurlyeq \mathrm{y}$ if and only if $y-x \in P$. We shall write $x<y$ to indicate $x \preccurlyeq y$ but $x \neq y$ while $\mathrm{x}<<\mathrm{y}$ will stand for $\mathrm{y}-\mathrm{x} \in$ int $\mathrm{P}$, where int $\mathrm{P}$ denotes the interior of the set $\mathrm{P}$. This cone $\mathrm{P}$ is called an order cone.

Definition 1.3[9] Let $\mathrm{E}$ be a Banach space and $\mathrm{P} \subset \mathrm{E}$ be an order cone. The order cone $\mathrm{P}$ is called normal if there exists $\mathrm{L}>0$ such that for all $\mathrm{x}, \mathrm{y} \in \mathrm{E}$,

$$
\theta \preccurlyeq \mathrm{x} \preccurlyeq \mathrm{y} \Rightarrow\|\mathrm{x}\| \leq \mathrm{L}\|\mathrm{y}\| \text {. }
$$

The least positive integer L satisfying the above inequality is called the normal constant of $P$.

Definition 1.4[9] Let $X$ be a nonempty set of E. Suppose that the map $\mathrm{d}: \mathrm{X} \times \mathrm{X} \rightarrow \mathrm{E}$ satisfies:

(d1). $\theta<d(x, y)$ for all $x, y \in X$ with $x \neq y$ and $\mathrm{d}(\mathrm{x}, \mathrm{y})=0$ if and only if $\mathrm{x}=\mathrm{y}$;

(d2). $d(x, y)=d(y, x)$ for all $x, y \in X$;

(d3). $d(x, y) \preccurlyeq d(x, z)+d(z, y)$ for all $x, y, z \in X$.

Then $\mathrm{d}$ is called a cone metric on $\mathrm{X}$ and $(\mathrm{X}, \mathrm{d})$ is called a cone metric space.

It is clear that the concept of a cone metric space is more general than that of a metric space.

Example 1.5 [9] Let $\mathrm{E}=\mathbb{R}^{2}, \mathrm{P}=\{(\mathrm{x}, \mathrm{y}) \in \mathrm{E}$ such that: $\mathrm{x}$, $\mathrm{y} \geq 0\} \subseteq \mathbb{R}^{2}, \mathrm{X}=\mathbb{R}$ and $\mathrm{d}: \mathrm{X} \times \mathrm{X} \rightarrow \mathrm{E}$ such that $\mathrm{d}(\mathrm{x}, \mathrm{y})=$ $(|\mathrm{x}-\mathrm{y}|, \alpha|\mathrm{x}-\mathrm{y}|)$, where $\alpha \geq 0$ is a constant. Then $(\mathrm{X}, \mathrm{d})$ is a cone metric space.

Definition 1.6[9] Let $(X, d)$ be a cone metric space .We say that $\left\{x_{n}\right\}$ is said to be

(i) a convergent sequence if for any $c>>\theta$, there is a natural number $\mathrm{N}$ such that for all $\mathrm{n}>\mathrm{N}, \mathrm{d}\left(\mathrm{x}_{\mathrm{n}}, \mathrm{x}\right)<<\mathrm{c}$, for some fixed $\mathrm{x}$ in $\mathrm{X}$. We denote this $\mathrm{X}_{\mathrm{n}} \rightarrow \mathrm{X}$ (as $\left.\mathrm{n} \rightarrow \infty\right)$.

(ii) a Cauchy sequence if for every $\mathrm{c}$ in $\mathrm{E}$ with $\mathrm{c}>>\theta$, there is a natural number $\mathrm{N}$ such that for all $\mathrm{n}, \mathrm{m}>\mathrm{N}$,

(iii) $\mathrm{d}\left(\mathrm{x}_{\mathrm{n}}, \mathrm{x}_{\mathrm{m}}\right)<<\mathrm{c}$.

(iv) a cone metric space $(\mathrm{X}, \mathrm{d})$ is said to be complete if every Cauchy sequence in $\mathrm{X}$ is convergent.

Lemma 1.7 [9]. Let $(X, d)$ be a cone metric space and $P$ be a normal cone with normal constant $\mathrm{L}$. Let $\left\{\mathrm{x}_{\mathrm{n}}\right\}$ and $\left\{\mathrm{y}_{\mathrm{n}}\right\}$ be two sequences in $\mathrm{X}$ with $\mathrm{x}_{\mathrm{n}} \rightarrow \mathrm{x}$ and $\mathrm{y}_{\mathrm{n}} \rightarrow \mathrm{y}$. Then $\mathrm{d}\left(\mathrm{x}_{\mathrm{n}}, \mathrm{y}_{\mathrm{n}}\right) \rightarrow$ $\mathrm{d}(\mathrm{x}, \mathrm{y})$ as $\mathrm{n} \rightarrow \infty$.

Remark 1.8 [7]. (1) If $E$ is real Banach space with a cone $\mathrm{P}$ and $\mathrm{a} \preccurlyeq \lambda \mathrm{a}$, where $\mathrm{a} \in \mathrm{P}$ and $0<\lambda<1$, then $\mathrm{a}=\theta$. (2) If $\mathrm{c} \in$ int $\mathrm{P}, \theta \preccurlyeq \mathrm{a}_{\mathrm{n}}$ and $\mathrm{a}_{\mathrm{n}} \rightarrow \theta$, then there exists a positive integer $\mathrm{N}$ such that $a_{n}<<$ c for all $n \geq N$. 
The concept of c-distance introduced by Y. J. Cho, et al. [7], which is a cone version of $\omega$-distance of Kada. et al. [10]

Definition 1.9[7]. Let $(X, d)$ be a cone metric space. Then a function $\mathrm{q}: \mathrm{X} \times \mathrm{X} \rightarrow \mathrm{E}$ is called a c-distance on $\mathrm{X}$ if the following are satisfied

(q1) $\theta \leqslant \mathrm{q}(\mathrm{x}, \mathrm{y})$ for all $\mathrm{x}, \mathrm{y} \in \mathrm{X}$;

(q2) $\mathrm{q}(\mathrm{x}, \mathrm{z}) \leqslant \mathrm{q}(\mathrm{x}, \mathrm{y})+\mathrm{q}(\mathrm{y}, \mathrm{z})$ for all $\mathrm{x}, \mathrm{y}, \mathrm{z} \in \mathrm{X}$;

(q3) for each $\mathrm{x} \in \mathrm{X}$ and $\mathrm{n} \geq 1$, if $\mathrm{q}\left(\mathrm{x}, \mathrm{y}_{\mathrm{n}}\right) \leqslant \mathrm{u}$ for some $\mathrm{u}=$ $\mathrm{u}_{\mathrm{x}} \in \mathrm{P}$, then $\mathrm{q}(\mathrm{x}, \mathrm{y}) \preccurlyeq \mathrm{u}$ whenever $\left\{\mathrm{y}_{\mathrm{n}}\right\}$ is a sequence in $\mathrm{X}$ convergent to a point $\mathrm{y} \in \mathrm{X}$.

(q4) for all $\mathrm{c} \in \mathrm{E}$ with $\theta<<\mathrm{c}$, there exists $\mathrm{e} \in \mathrm{E}$ with $0<<\mathrm{e}$ such that $\mathrm{q}(\mathrm{z}, \mathrm{x})<<$ e and $\mathrm{q}(\mathrm{z}, \mathrm{y})<<$ e imply $\mathrm{q}(\mathrm{x}, \mathrm{y})<<\mathrm{c}$.

Lemma 1.10 [7]. Let $(X, d)$ be a cone metric space and $q$ be a cone distance on $\mathrm{X}$. Let $\left\{\mathrm{x}_{\mathrm{n}}\right\}$ and $\left\{\mathrm{y}_{\mathrm{n}}\right\}$ be sequences in $\mathrm{X}$ and $\mathrm{x}, \mathrm{y}, \mathrm{z} \in \mathrm{X}$. Suppose that $\left\{\mathrm{u}_{\mathrm{n}}\right\}$ is a sequence in $\mathrm{P}$ converging to $\theta$. Then the following are holds:

(1) If $\mathrm{q}\left(\mathrm{x}_{\mathrm{n}}, \mathrm{y}\right) \preccurlyeq \preccurlyeq \mathrm{u}_{\mathrm{n}}$ and $\mathrm{q}\left(\mathrm{x}_{\mathrm{n}}, \mathrm{z}\right) \preccurlyeq \preccurlyeq \mathrm{u}_{\mathrm{n}}$, then $\mathrm{y}=\mathrm{z}$.

(2) If $\mathrm{q}\left(\mathrm{x}_{\mathrm{n}}, \mathrm{y}_{\mathrm{n}}\right) \preccurlyeq \mathrm{u}_{\mathrm{n}}$ and $\mathrm{q}\left(\mathrm{x}_{\mathrm{n}}, \mathrm{z}\right) \leqslant \mathrm{u}_{\mathrm{n}}$, then $\left\{\mathrm{y}_{\mathrm{n}}\right\}$ converges to $\mathrm{z}$.

(3) If $q\left(x_{n}, x_{m}\right) \preccurlyeq u_{n}$ form $>n$, then $\left\{x_{n}\right\}$ is a Cauchy sequence in $X$.

(4) If $\mathrm{q}\left(\mathrm{y}, \mathrm{x}_{\mathrm{n}}\right) \leqslant \mathrm{u}_{\mathrm{n}}$, then $\left\{\mathrm{x}_{\mathrm{n}}\right\}$ is a Cauchy sequence in $\mathrm{X}$.

\section{Fixed Point Theorems on C-distance}

Theorem 2.1. Let $(X, \subseteq$ ) be a partially ordered set and suppose that $(\mathrm{X}, \mathrm{d})$ is a complete cone metric space. Let $\mathrm{q}$ be a c-distance on $X$ and $f, g: X \rightarrow X$ be two continuous and weakly increasing mappings with respect to $ᄃ$. Suppose that there exists $\mathrm{a}_{1}, \mathrm{a}_{2}, \mathrm{a}_{3}, \mathrm{a}_{4}>0$ with $\mathrm{a}_{1}+\mathrm{a}_{2}+\mathrm{a}_{3}+2 \mathrm{a}_{4}<1$ such that

$$
q(f x, g y) \preccurlyeq a_{1} q(x, y)+a_{2} q(x, f x)+a_{3} q(y, g y)+a_{4} q(x, f y)
$$

and

$$
q(g x, f y) \preccurlyeq a_{1} q(x, y)+a_{2} q(x, g x)+a_{3} q(y, f y)+a_{4} q(x, g y)
$$

for all comparable $\mathrm{x}, \mathrm{y} \in \mathrm{X}$. Then $\mathrm{f}$ and $\mathrm{g}$ have a common fixed point $\mathrm{x}^{*} \in X$ X.If $\mathrm{v}=\mathrm{fv}=\mathrm{gv}$, then $\mathrm{q}(\mathrm{v}, \mathrm{v})=\theta$.

Proof: Let $\mathrm{x}_{0}$ be an arbitrary point in $\mathrm{X}$ and define a sequence $\left\{\mathrm{x}_{\mathrm{n}}\right\}$ in $\mathrm{X}$ as follows

$$
\mathrm{x}_{2 \mathrm{n}+1}=\mathrm{fx}_{2 \mathrm{n}} ; \mathrm{x}_{2 \mathrm{n}+2}=\mathrm{gx}_{2 \mathrm{n}+1} \quad \text { for all } \mathrm{n} \geq 0 \text {. }
$$

Since $f$ and $g$ are weakly increasing, we have $x_{1}=f_{x_{0}}$ 드 $\mathrm{gfx}_{0}=\mathrm{gx}_{1}=\mathrm{x}_{2}$ and

$\mathrm{x}_{2}=\mathrm{gx}_{1} \subseteq \mathrm{fgx}_{1}=\mathrm{fx}_{2}=\mathrm{x}_{3}$. Continuing this process, we have

$$
\mathrm{x}_{0} \text { 든 } \mathrm{x}_{1} \subseteq \mathrm{x}_{2} \subseteq \ldots \text { 드 } \mathrm{x}_{\mathrm{n}} \text { 드 } \mathrm{x}_{\mathrm{n}+1} \text { 드. }
$$

That is the sequence $\left\{x_{n}\right\}$ is non-decreasing. Since, $x_{2 n}$, $\mathrm{x}_{2 \mathrm{n}+1}$ are such that $\mathrm{x}_{2 \mathrm{n}}$ 드 $\mathrm{x}_{2 \mathrm{n}+1}$

by (1) we have

$$
\begin{gathered}
q\left(x_{2 n+1}, x_{2 n+2}\right)=q\left(f x_{2 n}, g x_{2 n+1}\right) \\
\preccurlyeq a_{1} q\left(x_{2 n}, x_{2 n+1}\right)+a_{2} q\left(x_{2 n}, f x_{2 n}\right)+a_{3} q\left(x_{2 n+1}, g x_{2 n+1}\right)+
\end{gathered}
$$

$$
\begin{gathered}
a_{4} q\left(x_{2 n}, x_{2 n+1}\right) \\
=a_{1} q\left(x_{2 n}, x_{2 n+1}\right)+a_{2} q\left(x_{2 n}, x_{2 n+1}\right)+a_{3} q\left(x_{2 n+1}, x_{2 n+2}\right)+a_{4} q\left(x_{2 n},\right. \\
\left.\quad x_{2 n+2}\right) \\
=\left(a_{1}+a_{2}\right) q\left(x_{2 n}, x_{2 n+1}\right)+a_{3} q\left(x_{2 n+1}, x_{2 n+2}\right)+a_{4} q\left(x_{2 n}, x_{2 n+1}\right)+a_{4} \\
q\left(x_{2 n}, x_{2 n+2}\right) \\
=\left(a_{1}+a_{2}+a_{4}\right) q\left(x_{2 n}, x_{2 n+1}\right)+\left(a_{3}+a_{4}\right) q\left(x_{2 n+1}, x_{2 n+2}\right) \\
\Rightarrow\left(1-\left(a_{3}+a_{4}\right)\right) q\left(x_{2 n+1}, x_{2 n+2}\right) \leqslant\left(a_{1}+a_{2}+a_{4}\right) q\left(x_{2 n}, x_{2 n+1}\right) \\
\Rightarrow q\left(x_{2 n+1}, x_{2 n+2}\right) \leqslant\left(a_{1}+a_{2}+a_{4}\right) /\left(1-\left(a_{3}+a_{4}\right)\right) q\left(x_{2 n}, x_{2 n+1}\right) . \\
\text { Let } \lambda=\left(a_{1}+a_{2}+a_{4}\right) /\left(1-\left(a_{3}+a_{4}\right)\right)<1 . \\
\Rightarrow q\left(x_{2 n+1}, x_{2 n+2}\right) \leqslant \lambda q\left(x_{2 n}, x_{2 n+1}\right) .
\end{gathered}
$$

Similarly, we can show that

$$
q\left(x_{2 n+2}, x_{2 n+3}\right) \leqslant \lambda q\left(x_{2 n+1}, x_{2 n+2}\right) .
$$

Therefore, we have

$\mathrm{q}\left(\mathrm{x}_{\mathrm{n}+1}, \mathrm{x}_{\mathrm{n}+2}\right) \leqslant \lambda \mathrm{q}\left(\mathrm{x}_{\mathrm{n}}, \mathrm{x}_{\mathrm{n}+1}\right) \leqslant \ldots \leqslant \lambda^{\mathrm{n}+1} \mathrm{q}\left(\mathrm{x}_{0}, \mathrm{x}_{1}\right)$ for all $\mathrm{n} \geq 1$.

Let $m>n$, then we have

$$
\begin{aligned}
\mathrm{q}\left(\mathrm{x}_{\mathrm{n}}, \mathrm{x}_{\mathrm{m}}\right) & \leqslant \mathrm{q}\left(\mathrm{x}_{\mathrm{n}}, \mathrm{x}_{\mathrm{n}+1}\right)+\ldots+\mathrm{q}\left(\mathrm{x}_{\mathrm{m}-1}, \mathrm{x}_{\mathrm{m}}\right) \\
& \leqslant \lambda^{\mathrm{n}} / 1-\lambda \mathrm{q}\left(\mathrm{x}_{0}, \mathrm{x}_{1}\right) .
\end{aligned}
$$

Therefore, we get that

$$
\mathrm{q}\left(\mathrm{x}_{\mathrm{n}}, \mathrm{x}_{\mathrm{m}}\right) \leqslant \lambda^{\mathrm{n}} / 1-\lambda \mathrm{q}\left(\mathrm{x}_{0}, \mathrm{x}_{1}\right)
$$

Thus by the Lemma (1.10) shows that $\left\{\mathrm{x}_{\mathrm{n}}\right\}$ is a Cauchy sequence in $X$. Since $X$ is complete, there exists a point $x^{*} \in$ $X$ such that $x_{n} \rightarrow x^{*}$ as $n \rightarrow \infty$. Since $f$ is continuous, one has

$$
\mathrm{x}^{*}=\lim _{n \rightarrow \infty} f x_{2 n}=\mathrm{fx}^{*} .
$$

This shows that $x^{*}$ is a fixed point of $f$.

Similarly we can prove that $x^{*}$ is a fixed point of $g$.

Suppose, $v=f v=g v$. Since $v \subseteq v$ by (1) we have

$$
\begin{gathered}
\mathrm{q}(\mathrm{v}, \mathrm{v})=\mathrm{q}(\mathrm{fv}, \mathrm{gv}) \\
\preccurlyeq \mathrm{a}_{1} \mathrm{q}(\mathrm{v}, \mathrm{v})+\mathrm{a}_{2} \mathrm{q}(\mathrm{v}, \mathrm{fv})+\mathrm{a}_{3} \mathrm{q}(\mathrm{v}, \mathrm{gv})+\mathrm{a}_{4} \mathrm{q}(\mathrm{v}, \mathrm{fv}) \\
\preccurlyeq \mathrm{a}_{1} \mathrm{q}(\mathrm{v}, \mathrm{v})+\mathrm{a}_{2} \mathrm{q}(\mathrm{v}, \mathrm{v})+\mathrm{a}_{3} \mathrm{q}(\mathrm{v}, \mathrm{v})+\mathrm{a}_{4} \mathrm{q}(\mathrm{v}, \mathrm{v}) \\
\leqslant\left(\mathrm{a}_{1}+\mathrm{a}_{2}+\mathrm{a}_{3}+\mathrm{a}_{4}\right) \mathrm{q}(\mathrm{v}, \mathrm{v}) .
\end{gathered}
$$

Since, $a_{1}+a_{2}+a_{3}+a_{4}<1$, we have $q(v, v)=\theta$.

This completes the proof.

Theorem 2.2. Let $(X$, 드) be a partially ordered set and suppose that $(\mathrm{X}, \mathrm{d})$ is a complete cone metric space and $\mathrm{P}$ ia a normal cone with normal constant $\mathrm{K}$. Let $\mathrm{q}$ be a c-distance on $\mathrm{X}$ and $\mathrm{f}, \mathrm{g}: \mathrm{X} \rightarrow \mathrm{Xbe}$ two weakly increasing mappings with respect to $ᄃ$. Suppose that there exists $\mathrm{a}_{\mathrm{i}}>0(\mathrm{i}=1,2,3,4,5)$ with $a_{1}+a_{2}+a_{3}+2 a_{4}+2 a_{5}<1$ such that $f$, g satisfy conditions (1) and (2) of the above Theorem 2.1. If the following are hold:

$$
\inf \{\|q(x, y)\|+\|q(x, f x)\|: x \in X\}>0,
$$

for all $y \in X$ with $y \neq f y$,

and

$$
\inf \{\|\mathrm{q}(\mathrm{x}, \mathrm{y})\|+\|\mathrm{q}(\mathrm{x}, \mathrm{gx})\|: \mathrm{x} \in \mathrm{X}\}>0,
$$


for all $\mathrm{y} \in \mathrm{X}$ with $\mathrm{y} \neq \mathrm{gy}$,

Then $f$ and $g$ have a common fixed point $x^{*} \in X$. If $v=f v=$ $\mathrm{gv}$, then $\mathrm{q}(\mathrm{v}, \mathrm{v})=\theta$.

Proof: Let $\mathrm{x}_{0}$ be an arbitrary point in $\mathrm{X}$ and define a sequence $\left\{\mathrm{x}_{\mathrm{n}}\right\}$ in $\mathrm{X}$ as follows

$$
\mathrm{x}_{2 \mathrm{n}+1}=\mathrm{fx}_{2 \mathrm{n}} ; \mathrm{x}_{2 \mathrm{n}+2}=\mathrm{gx}_{2 \mathrm{n}+1} \text { for all } \mathrm{n} \geq 0 .
$$

As in the proof of the above Theorem 2.1, we have

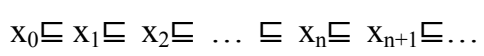

Moreover, the sequence $\left\{x_{n}\right\}$ converges to a point $x^{*} \in X$ and

$$
\mathrm{q}\left(\mathrm{x}_{\mathrm{n}}, \mathrm{x}_{\mathrm{m}}\right) \leqslant \lambda^{\mathrm{n}} / 1-\lambda \mathrm{q}\left(\mathrm{x}_{0}, \mathrm{x}_{1}\right) \text { for all } \mathrm{m}>\mathrm{n} \geq 1,
$$

where, $\lambda=\left(a_{1}+a_{2}+a_{4}+2 a_{5}\right) /\left(1-\left(a_{3}+a_{4}\right)\right)<1$.

From $\left(\mathrm{q}_{3}\right)$, it follows that

$$
\mathrm{q}\left(\mathrm{x}_{\mathrm{n}}, \mathrm{x}^{*}\right) \leqslant \lambda^{\mathrm{n}} / 1-\lambda \mathrm{q}\left(\mathrm{x}_{0}, \mathrm{x}_{1}\right) \text { for all } \mathrm{n} \geq 1 .
$$

Since, $\mathrm{P}$ is a normal cone with normal constant $\mathrm{K}$, we have for all $m>n \geq 1$

$$
\left\|\mathrm{q}\left(\mathrm{x}_{\mathrm{n}}, \mathrm{x}_{\mathrm{m}}\right)\right\| \preccurlyeq \preccurlyeq \mathrm{KK} \lambda^{\mathrm{n}} / 1-\lambda \frac{\lambda^{\mathrm{n}}}{1-\lambda}\left\|\mathrm{q}\left(\mathrm{x}_{0}, \mathrm{x}_{1}\right)\right\|
$$

and

$$
\left\|\mathrm{q}\left(\mathrm{x}_{\mathrm{n}}, \mathrm{x}^{*}\right)\right\| \leqslant K \lambda^{\mathrm{n}} / 1-\lambda\left\|\mathrm{q}\left(\mathrm{x}_{0}, \mathrm{x}_{1}\right)\right\|
$$

If $\mathrm{x}^{*} \neq \mathrm{fx}^{*}$, then by (3), (4) and (5) we have

$$
\begin{gathered}
0<\inf \left\{\left\|\mathrm{q}\left(\mathrm{x}, \mathrm{x}^{*}\right)\right\|+\|\mathrm{q}(\mathrm{x}, \mathrm{fx})\|: \mathrm{x} \in \mathrm{X}\right\} \\
\leq \inf \left\{\left\|\mathrm{q}\left(\mathrm{x}_{2 \mathrm{n}}, \mathrm{x}^{*}\right)\right\|+\left\|\mathrm{q}\left(\mathrm{x}_{2 \mathrm{n}}, \mathrm{fx}_{2 \mathrm{n}}\right)\right\|: \mathrm{n} \geq 1\right\} \\
\leq \inf \left\{\left\|\mathrm{q}\left(\mathrm{x}_{2 \mathrm{n}}, \mathrm{x}^{*}\right)\right\|+\left\|\mathrm{q}\left(\mathrm{x}_{2 \mathrm{n}}, \mathrm{x}_{2 \mathrm{n}+1}\right)\right\|: \mathrm{n} \geq 1\right\} \\
\leq \inf K \lambda^{\mathrm{n}} / 1-\lambda \frac{\lambda^{2 \mathrm{n}}}{1-\lambda}\left\|\mathrm{q}\left(\mathrm{x}_{0}, \mathrm{x}_{1}\right)\right\|+K \lambda^{\mathrm{n}} / 1-\lambda \frac{\lambda^{2 \mathrm{n}}}{1-\lambda}\left\|\mathrm{q}\left(\mathrm{x}_{0}, \mathrm{x}_{1}\right)\right\|: \\
\mathrm{n} \geq 1\}=0 .
\end{gathered}
$$

This is a contraction. Therefore $\mathrm{x}^{*}=\mathrm{fx}^{*}$.

Similarly, we can prove that $\mathrm{x}^{*}=\mathrm{gx}^{*}$.

If $\mathrm{v}=\mathrm{fv}=\mathrm{gv}$, then we prove $\mathrm{q}(\mathrm{v}, \mathrm{v})=\theta$ in the final part proof of the above Theorem 2.1.

This completes the proof.

Remark 2.3 If we choose $a_{1}=\alpha, a_{2}=\beta, a_{3}=\gamma$, and $a_{4}=0$ in the above Theorem 2.1, then we get the Theorem 3.3 of [7].

Remark 2.4 If we choose $a_{1}=\alpha, a_{2}=\beta, a_{3}=\gamma$, and $a_{4}=a_{5}$ $=0$ in the above Theorem 2.2, then we get the Theorem 3.4 of [7].

Conclusion 2.5. In this paper, the author has extended the results of Y. J. Cho, et al. [7]

\section{REFERENCES}

[1] M. Abbas and G. Jungck, Common fixed point results for non-commuting mappings without continuity in cone metric spaces, J. Math. Anal. Appl. 341(2008) 416-420.

[2] M. Abbas, B. E. Rhoades, Fixed and periodic point results in cone metric spaces, Appl. Math. Lett.21 (2008)511-515.

[3] I. Altun, B. Damnjanovic, D. Djoric, Fixed point and common fixed point theorems on ordered cone metric spaces, Appl. Math. Lett. (2009)doi:10.1016/j.aml.2009.09.016.

[4] I. Altun, B. Durmaz, Some fixed point theorems on ordered cone metric spaces, Rend. Circ. Mat. Palermo 58(2009) 319-325.

[5] M. Amari, D. El Moutawakil, Some new common fixed point theorems under strict contractive conditions, J. Math. Anal. Appl. 270(2002)181-188.

[6] M. Arshad, A. Azam, P. Vetro, Some common fixed point results on cone metric spaces, Fixed Point Theory Appl. (2009)11, Article ID 493965.

[7] J. Cho, R. Saadati, and Sh. Wang, Common fixed point theorems on generalized distance in ordered cone metric spaces. Compt. Math. Appl. 61(2011), 1254-1260.

[8] Guangxing Song, Xiaoyan Sun, Yian Zhao, Guotao Wang, New common fixed point theorems for maps on cone metric spaces, Appl. Math. Lett.32 (2010)1033-1037.

[9] L. G. Huang, X. Zhang, Cone metric spaces and fixed point theorems of contractive mappings, J. Math. Anal. Appl. 332(2) (2007)1468-1476.

[10] O. Kada, T. Suzuki, W. Takahashi, Nonconvex minimization theorems and fixed point theorems in complete metric spaces, Math. Japon.44 (1996) 381-391.

[11] Z. Kadelburg, M. Pavlović, S. Radenović, Common fixed point theorems for ordered contractions and quasi-contractions in ordered cone metric spaces, Comput. Math. Appl. 59 (2010) 3148-3159.

[12] S. Radenović, B.E. Rhoades, Fixed point theorem for two non-self-mappings in cone metric spaces, Comput. Math. Appl. 57 (2009) 1701-1707.

[13] W. Shatanawi, Partially ordered cone metric spaces and coupled fixed point results, Comput. Math. Appl. (2010) doi:10.1016/j.camwa.2010.08.074. 